\title{
Effect of surface BRDF of various land cover types on geostationary observations of tropospheric $\mathrm{NO}_{2}$
}

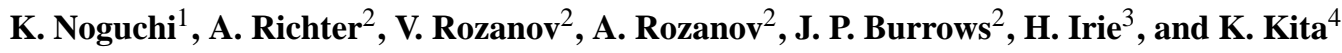 \\ ${ }^{1}$ Faculty of Science, Nara Women's University, Nara, Japan \\ ${ }^{2}$ Institute of Environmental Physics, University of Bremen, Bremen, Germany \\ ${ }^{3}$ Center for Environmental Remote Sensing, Chiba University, Chiba, Japan \\ ${ }^{4}$ Faculty of Science, Ibaraki University, Mito, Japan \\ Correspondence to: K. Noguchi (nogu@ics.nara-wu.ac.jp)
}

Received: 30 January 2014 - Published in Atmos. Meas. Tech. Discuss.: 7 April 2014

Revised: 27 August 2014 - Accepted: 10 September 2014 - Published: 10 October 2014

\begin{abstract}
We investigated the effect of surface reflectance anisotropy, bidirectional reflectance distribution function (BRDF), on satellite retrievals of tropospheric $\mathrm{NO}_{2}$. We assume the geometry of geostationary measurements over Tokyo, which is one of the worst air-polluted regions in East Asia. We calculated air mass factors (AMF) and box AMFs (BAMF) for tropospheric $\mathrm{NO}_{2}$ to evaluate the effect of BRDF by using the radiative transfer model SCIATRAN. To model the BRDF effect, we utilized the Moderate Resolution Imaging Spectroradiometer (MODIS) products (MOD43B1 and MOD43B2), which provide three coefficients to express the RossThick-LiSparse reciprocal model, a semi-empirical and kernel-based model of BRDF. Because BRDF depends on the land cover type, we also utilized the High Resolution Land-Use and Land-Cover Map of the Advanced Land Observing Satellite (ALOS)/Advanced Visible and Near Infrared Radiometer type 2 (AVNIR-2), which classifies the ground pixels over Tokyo into six main types: water, urban, paddy, crop, deciduous forest, and evergreen forest. We first develop an empirical model of the three BRDF coefficients for each land cover type over Tokyo and then apply the model to the calculation of land-cover-type-dependent AMFs and BAMFs. Results show that the variability of AMF among the land types is up to several tens of percent, and if we neglect the reflectance anisotropy, the difference with AMFs based on BRDF reaches $10 \%$ or more. The evaluation of the BAMFs calculated shows that not considering BRDF will cause large errors if the concentration of $\mathrm{NO}_{2}$ is high close to the surface, although the importance of BRDF for AMFs decreases for large aerosol optical depth (AOD).
\end{abstract}

\section{Introduction}

Nitrogen dioxide $\left(\mathrm{NO}_{2}\right)$ plays an important role in tropospheric chemistry, and has been measured from space since the late 1990s. The spaceborne measurements from the Global Ozone Monitoring Experiment (GOME) (Burrows et al., 1999) and the Scanning Imaging Absorption Spectrometer for Atmospheric Cartography (SCIAMACHY) (Bovensmann et al., 1999) successfully provided the horizontal distributions of several tropospheric minor constituents including $\mathrm{NO}_{2}$. The GOME and SCIAMACHY instruments have spatial resolutions of $40 \mathrm{~km} \times 320 \mathrm{~km}$ and $30 \mathrm{~km} \times 60 \mathrm{~km}$, respectively. Improved spatial resolution of $13 \mathrm{~km} \times 24 \mathrm{~km}$ (nadir mode) is achieved with the Ozone Monitoring Instrument (OMI) onboard the Earth Observing System Aura, launched in 2004 (Levelt et al., 2006), followed by GOME-2 with a resolution of $40 \mathrm{~km} \times 80 \mathrm{~km}$ (Callies et al., 2000).

In previous studies, it was shown that measurements at such a high spatial resolution need more realistic parameters such as surface pressure, surface albedo, and reflectivity to derive accurate tropospheric $\mathrm{NO}_{2}$ vertical column densities (VCDs) (Zhou et al., 2009; Boersma et al., 2011; Heckel et al., 2011; Russell et al., 2011). The authors indicated that the error from surface albedo was especially large. For example, Heckel et al. (2011) showed that the spread of $\mathrm{NO}_{2}$ air mass factor (AMF) values over land in a typical coastal area (around San Francisco) increases by $\pm 30 \%$ on average if they used the surface albedo with high spatial resolution instead of coarse albedo which had been utilized in the previous retrievals. Russell et al. (2011) showed that using surface 
reflectance with a high resolution in $\mathrm{NO}_{2}$ retrievals diminished a false enhancement of $\mathrm{NO}_{2}$ which were retrieved with a coarse surface albedo over an unpolluted region. The reduction of $\mathrm{NO}_{2}$ amounts was up to $30 \%$.

One of the difficulties of treating surface albedo is its complex dependence on the incidence and outgoing directions of light, which is expressed as the bidirectional reflectance distribution function (BRDF). Because the precise observations of BRDF for the entire global surface are difficult, nearly all previous studies assumed a Lambertian equivalent reflectivity (LER) surface for the operational retrieval of the $\mathrm{NO}_{2}$ products. However, Zhou et al. (2010) pointed out the importance of $\mathrm{BRDF}$ for tropospheric $\mathrm{NO}_{2}$ retrievals from OMI measurements, where viewing zenith angles on the ground surface are $0-70^{\circ}$ and the overpass time is 13:45 LT at the equator, showing that the differences between the tropospheric $\mathrm{NO}_{2}$ VCDs using LER and BRDF are $0-20 \%$. In their study, viewing angles largely changed with relatively constant solar zenith angles as OMI is aboard a sun-synchronous satellite. Lin et al. (2013) accounts for the BRDF effect in the retrievals of the tropospheric $\mathrm{NO}_{2}$ column density over China using OMI measurements, and the authors showed that without consideration of the BRDF in the $\mathrm{NO}_{2}$ retrievals (OMI-based LER product was used for the surface albedo), the tropospheric $\mathrm{NO}_{2}$ VCDs decrease by $7 \%$ on average with a variability of up to $-45 \%$ for individual grid pixels compared to the retrievals with BRDF.

In the present study, we discuss the effect of BRDF on tropospheric $\mathrm{NO}_{2}$ retrievals in future geostationary measurements from the Geostationary Mission for Meteorology and Air Pollution (GMAP-Asia) in Japan (Akimoto et al., 2008, 2009), where a horizontal resolution of $10 \mathrm{~km} \times 10 \mathrm{~km}$ or less is planned. The GMAP-Asia aims to monitor air pollution in Asia, and the present study focuses on the Tokyo region (the Kanto Plain), which is one of the most polluted regions in Asia. Discussion of the effect of BRDF on geostationary measurements is also important since solar zenith angles and azimuth angles change largely throughout the day in geostationary measurements, much more so than for low earth orbits. The effect of BRDF can be critical, particularly if the diurnal variation of a tropospheric species is to be determined. The nature of BRDF of a given surface is largely dependent on the land cover type. Therefore, we first develop an empirical model of BRDF with consideration of various land cover types in the Tokyo area, and then apply the model to the evaluation of the BRDF effect on tropospheric $\mathrm{NO}_{2}$ retrievals.

\section{Method}

\subsection{BRDF data}

Following the method proposed by Zhou et al. (2010), we utilized the BRDF products derived from Moderate Reso-

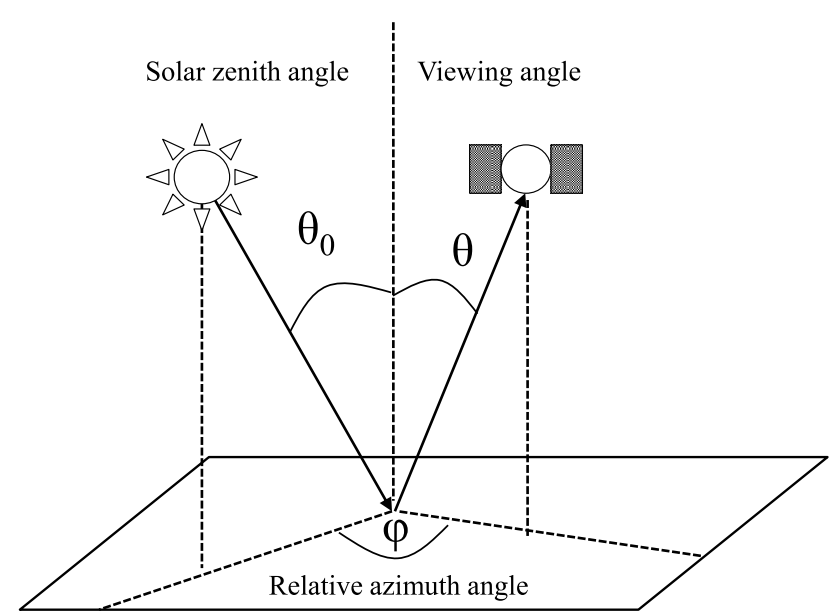

Figure 1. Definition of geometry angles of BRDF.

lution Imaging Spectroradiometer (MODIS) measurements (Justice et al., 1998). MODIS is aboard the Terra (EOS AM) and Aqua (EOS PM) satellites, and has six spectral bands in the wavelength region from $400 \mathrm{~nm}$ to $14.4 \mu \mathrm{m}$ with spatial resolutions of 250, 500 and $1000 \mathrm{~m}$, depending on the bands. In the present study, we utilized the channel $3(459-479 \mathrm{~nm})$ data.

The MODIS BRDF products adopted the RossThickLiSparse reciprocal model, which is a semi-empirical and kernel-based model of BRDF (Lucht et al., 2000). The kernel components include the isotropic reflection effect, the volume scattering effect, and the surface scattering and geometric shadow casting effect:

$$
\begin{gathered}
\operatorname{BRDF}\left(\theta_{0}, \theta, \phi, \lambda\right)=(1 / \pi)\left\{f_{\text {iso }}(\lambda)+f_{\mathrm{vol}}(\lambda)\right. \\
\left.K_{\mathrm{vol}}\left(\theta_{0}, \theta, \phi\right)+f_{\mathrm{geo}}(\lambda) K_{\mathrm{geo}}\left(\theta_{0}, \theta, \phi\right)\right\},
\end{gathered}
$$

where $\theta_{0}$ is the solar zenith angle (SZA), $\theta$ is the viewing angle from the satellite, $\phi$ is the relative azimuth angle, $\lambda$ is the wavelength, and $K_{\text {vol }}$ and $K_{\text {geo }}$ are the volumetric (RossThick) and geometric scattering (LiSparse-R) kernels, respectively (Roujean et al., 1992). This BRDF definition separates the dependence of BRDF on wavelength and the solar zenith and viewing angles. The definition of the three angles of the geometry, $\theta_{0}, \theta$, and $\phi$, is explained in detail in Fig. 1 . The three coefficients, $f_{\text {iso }}, f_{\text {vol }}$, and $f_{\text {geo }}$, are determined from MODIS observations. The first coefficient, $f_{\text {iso }}$, represents the component of non-directional reflectance while other two coefficients, $f_{\mathrm{vol}}$ and $f_{\text {geo }}$, are related with the directional components of the surface reflectance. The details of these coefficients are described in Roujean et al. (1992) and Zhou et al. (2010). The spatial distributions of $f_{\text {iso }}, f_{\text {vol }}$, and $f_{\text {geo }}$ over the Tokyo area were analyzed by Noguchi et al. (2012).

To discuss the BRDF effect, we utilized not only the MODIS-derived BRDF but also approximations of BRDF in the calculation of the air mass factor (AMF) and the box air 
Table 1. Definition of surface albedo types used in the present study.

\begin{tabular}{lll}
\hline Albedo type & $\begin{array}{l}\text { Reflectance nomenclature of } \\
\text { Nicodemus et al. (1977) }\end{array}$ & $\begin{array}{l}\text { Definition and implementation } \\
\text { in the present study }\end{array}$ \\
\hline BRF (bidirectional reflectance factors) & BRF & $\begin{array}{l}\text { Angle dependence }\left(\theta_{0}, \theta, \phi\right) \text { is fully } \\
\text { considered, but treated as Lambertian equivalent } \\
\text { reflectivity (LER) in RTM }\end{array}$ \\
\hline $\begin{array}{l}\text { BSA } \\
\text { (black-sky albedo) }\end{array}$ & Directional hemispheric reflectance & $\begin{array}{l}\text { Integral of the BRDF over all viewing } \\
\text { geometries. Only SZA dependence is considered, } \\
\text { and treated as LER in RTM }\end{array}$ \\
\hline $\begin{array}{l}\text { WSA } \\
\text { (white-sky albedo) }\end{array}$ & Bihemispherical reflectance & $\begin{array}{l}\text { No consideration of angle } \\
\text { dependence, and treated as LER in RTM }\end{array}$ \\
\hline
\end{tabular}

MODIS pixel $(1 \mathrm{~km} \times 1 \mathrm{~km})$

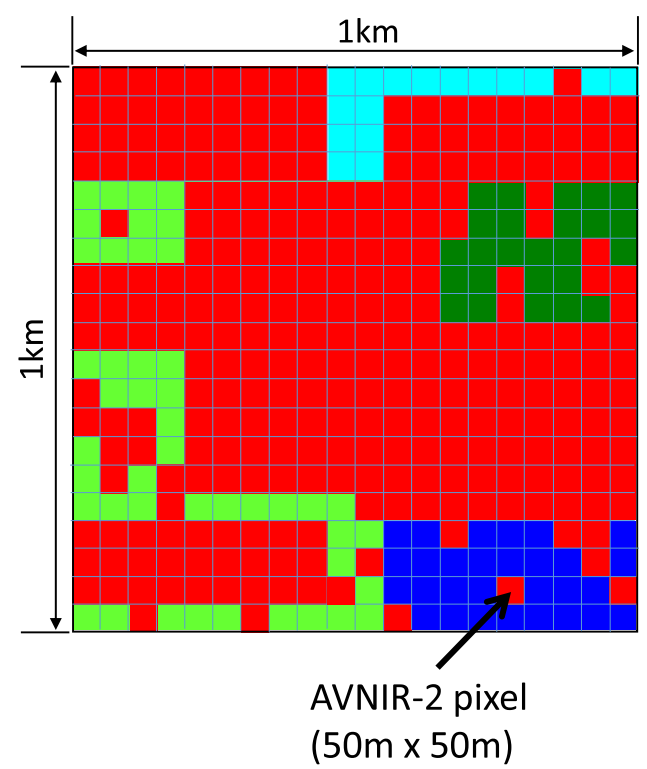

Figure 2. Schematic of the MODIS and AVNIR-2 pixel sizes. For example, the dominance of the land cover type shown in red for the MODIS pixel is calculated by dividing the number of the pixels in red $(=285)$ by the number of all the pixels $(=400)$.

mass factor (BAMF) of the tropospheric $\mathrm{NO}_{2}$. Table 1 explains the differences among the approximations used. We calculated AMF and BAMF not only for BRDF but also for bidirectional reflectance factors (BRF), black-sky albedo (BSA), and white-sky albedo (WSA) to compare with the results among those definitions. In the reflectance nomenclature of Nicodemus et al. (1977), BSA and WSA are so called directional hemispheric reflectance and bihemispherical reflectance, respectively. The three BRDF parameters, $f_{\text {iso }}, f_{\text {vol }}$, and $f_{\text {geo }}$, are included in the MODIS BRDF product, MOD43B1 (Schaaf et al., 2002). We use the product MOD43B2 for a check of the data quality. The spatial resolution of the three BRDF parameters which we utilized in the present study is $1 \mathrm{~km} \times 1 \mathrm{~km}$. The values of BRF, BSA, and WSA are calculated for a given geometry based on MODIS parameters. Lucht et al. (2000) proposed and Zhou et al. (2010) also utilized a very good and simple approximation with a third-degree polynomial to calculate the numerical integral of $K_{\mathrm{vol}}$ and $K_{\text {geo }}$ with respect to $\theta$ and $\phi$ :

$$
\begin{aligned}
& \operatorname{BSA}\left(\theta_{0}, \lambda\right)=f_{\text {iso }}(\lambda)+f_{\text {vol }}(\lambda)(-0.007574 \\
& \left.\quad-0.070987 \theta_{0}^{2}+0.307588 \theta_{0}^{3}\right)+f_{\text {geo }}(\lambda)(-1.284909 \\
& \left.\quad-0.166314 \theta_{0}^{2}+0.041840 \theta_{0}^{3}\right) .
\end{aligned}
$$

In a similar way, Lucht et al. (2000) gave the values of the numerical integral of $K_{\mathrm{vol}}$ and $K_{\text {geo }}$ with respect to all the angles $\left(\theta_{0}, \theta\right.$, and $\left.\phi\right)$ :

$\operatorname{WSA}(\lambda)=f_{\text {iso }}(\lambda)+0.189184 f_{\text {vol }}(\lambda)-1.377622 f_{\text {geo }}(\lambda)$.

In the subsequent radiative transfer model (RTM), these fixed values are implemented as LER. This means that the BRF, WSA, and BSA are all treated as LER values when the AMF and BAMFs are calculated with the RTM. As for BRDF, the RTM directly reads the three parameters and then calculates $\mathrm{AMF}$ and BAMF considering the BRDF effect.

\subsection{Land cover type data}

To take into account land cover types in the calculation of BRDF and other albedo types, we utilized the High Resolution Land-Use and Land-Cover Map of Advanced Land Observing Satellite (ALOS)/Advanced Visible and Near Infrared Radiometer type 2 (AVNIR-2) (Fukue et al., 1997). The spatial resolution of the data set is approximately $50 \mathrm{~m} \times 50 \mathrm{~m}$. As the grid size of AVNIR-2 is much smaller than that of MODIS, one MODIS grid pixel includes 400 pixels of AVNIR-2 (Fig. 2). Since there are few MODIS pixels which consist of only one land cover type, we define the most frequent land cover type within each MODIS grid pixel as the representative land cover type of the pixel. Figure 3 shows the most dominant land cover type for each MODIS grid pixel over Tokyo. The land cover types which we focus on in the present study are summarized in Table 2. 


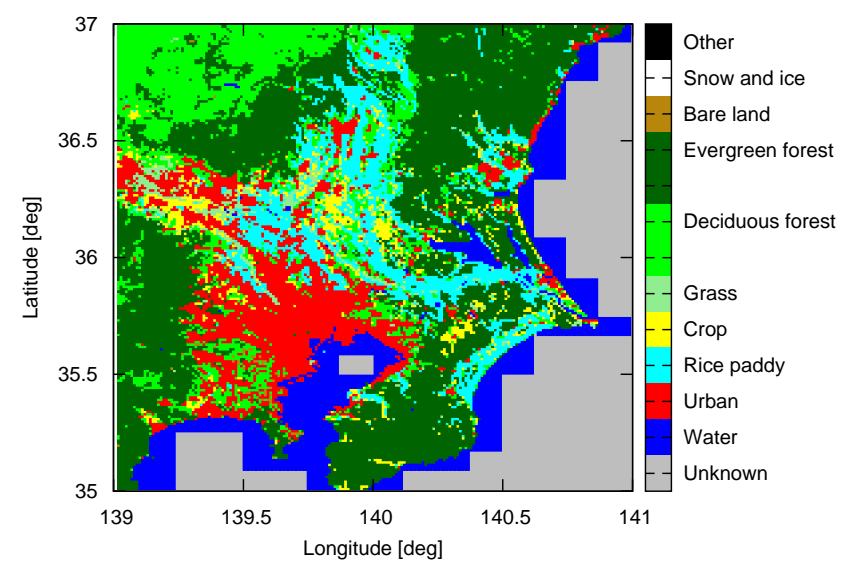

Figure 3. Land cover type map over the Kanto Plain derived from AVNIR-2. The grid size is changed to a $1 \mathrm{~km}$ square, which is the MODIS pixel size, from the AVNIR-2 original size of a $50 \mathrm{~m}$ square.

\subsection{Atmospheric and geometric scenarios for calculation of AMFs and BAMFs with SCIATRAN}

We calculated the AMFs and BAMFs of the tropospheric $\mathrm{NO}_{2}$ with the RTM SCIATRAN (version 3.1.29), which was developed to perform radiative transfer modeling for the purpose of the measurements of the earth's atmosphere (Rozanov et al., 2005, 2014). SCIATRAN can perform radiative transfer calculations properly accounting for the spherical shape of the earth's atmosphere including refraction. In this study, the discrete-ordinates method, which is one of the options provided by SCIATRAN, was selected to solve the integro-differential radiative transfer equation in pseudospherical mode.

For the simulations, appropriate atmospheric and geometric scenarios need to be defined. We defined 143 atmospheric layers between the altitudes of 0 and $100 \mathrm{~km}$ with a vertical resolution of $200 \mathrm{~m}(0-10 \mathrm{~km}), 500 \mathrm{~m}(10-12 \mathrm{~km})$, and $1 \mathrm{~km}(12-100 \mathrm{~km})$. We used a fixed $\mathrm{NO}_{2}$ vertical profile without seasonal or local time changes (Fig. 4). The scientific requirement team of the GMAP-Asia project provided this $\mathrm{NO}_{2}$ profile data, which is based on the measurements conducted by the TRACE-P aircraft mission (Jacob et al., 2003) and numerical simulations of the WRF-Chem model version 3.0.1 (Grell et al., 2005) with the conditions defined in Takigawa et al. (2007) and also in the CHASER model (Sudo et al., 2002). Pressure and temperature were taken from the US standard atmosphere 1976 (the average of midlatitudes). As for aerosols, we adopted a typical mixing state for urban aerosols described in Hess et al. (1998) with the options prepared by SCIATRAN, following Noguchi et al. (2011). Table 3 summarizes the details of the aerosol conditions assumed in the present study. We also assume a vertical profile of the extinction coefficient with a scale height of $3 \mathrm{~km}$ and
Table 2. Land cover type and its identification number (ID) in the AVNIR-2 data set.

\begin{tabular}{ll}
\hline Land cover type & ID \\
\hline Water & 1 \\
Urban & 2 \\
Paddy & 3 \\
Crop & 4 \\
Deciduous forest & 6 \\
Evergreen forest & 8 \\
\hline
\end{tabular}

an aerosol optical depth (AOD) of 0.2 and 1.0 for comparison at a wavelength of $550 \mathrm{~nm}$.

For the definition of the geometric scenario in SCIATRAN, three angles are needed; the SZA, the viewing angle from the satellite, and the relative azimuth angle (the angle between the sun and the satellite or an observation point at the ground surface). The definitions of those angles in SCIATRAN are depicted in Noguchi et al. (2011). We prepared a diurnal variation of SZAs and relative azimuth angles for summer and winter solstices as shown in Table 3 in Noguchi et al. (2011). The viewing angle at the surface is constant $\left(46.4^{\circ}\right)$ for a geostationary satellite, which is chosen to be located at the altitude of $36000 \mathrm{~km}$ over $120^{\circ} \mathrm{E}$ on the equator.

\section{Results}

\subsection{Empirical model of BRDF parameters $\left(f_{\text {iso }}, f_{\text {vol }}, f_{\text {geo }}\right)$ specific to land cover types}

To obtain an empirical model of the typical BRDF parameters for each land cover type over Tokyo, we computed monthly averages of the BRDF parameters, $f_{\text {iso }}, f_{\text {vol }}$, and $f_{\text {geo }}$, grouped by MODIS pixels having the same land cover type. As is described in Sect. 2.2, we classify each MODIS pixel to have one specific land cover type, which is the most dominant land cover type in the MODIS pixel. To select typical MODIS pixels which represent each land cover type, we defined a threshold for the percentage of the most frequent AVNIR-2 land cover type in a MODIS pixel. As a sensitivity study, the values of $f_{\text {iso }}, f_{\text {vol }}$, and $f_{\text {geo }}$ were compared for different values of the land cover threshold (90, 95, and $100 \%)$. Different values were used for crop land cover type (60\%), owing to the small number of MODIS pixels with a high ratio dominance of crop. Then, we created monthly averages of the three BRDF parameters for each land cover type. For example, we averaged all of the BRDF parameters, $f_{\text {iso }}, f_{\text {vol }}$, and $f_{\text {geo }}$, using only those MODIS pixels which include $95 \%$ or more of the "water" type of AVNIR-2 pixels to obtain the monthly mean BRDF parameters of the water type for the threshold of $95 \%$.

The sensitivity study for the threshold shows that the monthly averages of $f_{\text {iso }}, f_{\mathrm{vol}}$, and $f_{\text {geo }}$ for water, deciduous 


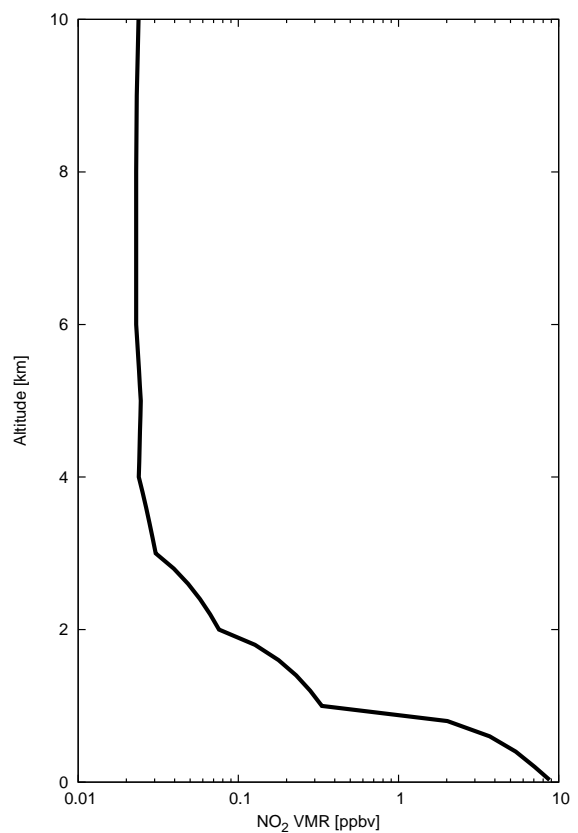

(b)

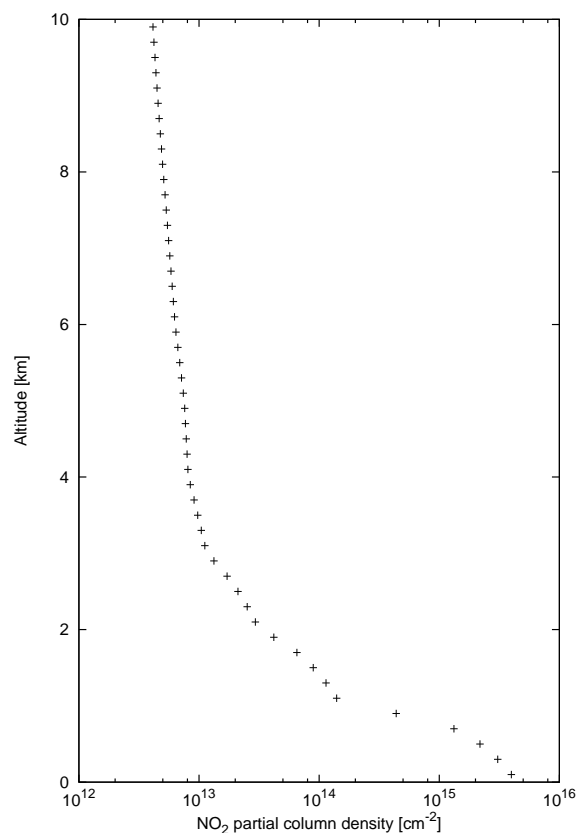

Figure 4. Vertical profiles of (a) $\mathrm{NO}_{2}$ volume mixing ratio (VMR) and (b) $\mathrm{NO}_{2}$ partial column density of each layer. Tropospheric $(0-10 \mathrm{~km})$ total column density is $1.1 \times 10^{16}\left[\mathrm{~cm}^{-2}\right]$.

Table 3. Aerosol scenario.

\begin{tabular}{lrlll}
\hline Layer no. & Altitude range & Aerosol types & $\begin{array}{l}\text { Components and number } \\
\text { mixing ratios }\end{array}$ & $\begin{array}{l}\text { Relative } \\
\text { humidity }\end{array}$ \\
\hline$\# 1$ & $0-2 \mathrm{~km}$ & Urban & $\begin{array}{l}\text { water soluble: } 0.177 \\
\text { insoluble: } 0.949 \times 10^{-5}\end{array}$ & $80 \%$ \\
& & & $\begin{array}{l}\text { soot: } 0.823 \\
\text { water soluble: } 0.458 \\
\text { insoluble: } 0.261 \times 10^{-4}\end{array}$ & $70 \%$ \\
$\# 2$ & $2-10 \mathrm{~km}$ & Continental average & \\
& & & $\begin{array}{l}\text { soot: } 0.542 \\
\text { sulfate: } 1\end{array}$ & $0 \%$ \\
m3 & $10-30 \mathrm{~km}$ & Sulfate & meteoric dust: 1 & $0 \%$ \\
\hline
\end{tabular}

forest, and evergreen forest do not vary much if the threshold is increased from 90 to $100 \%$ (see the Supplement). For the urban and rice paddy types, however, the results for 90 and $95 \%$ are similar, but that for $100 \%$ is different from the others. This is because the number of the pixels for $100 \%$ is very small, only 20 pixels out of a total of 4248 urban-type pixels and just one pixel for a total of 3418 rice-paddy-type pixels.

Therefore we decided to take a threshold percentage of $95 \%$ land cover type dominance to obtain an empirical model of monthly averages of the BRDF parameters, $f_{\text {iso }}$, $f_{\mathrm{vol}}$, and $f_{\mathrm{geo}}$, except for crop, for which we took a threshold of $70 \%$. Figure 5 shows the results. We can see that the urban type, which is a major land cover type in the polluted region, has small seasonal dependence. This is consistent with the fact that urban surface features (e.g., buildings and roads) are basically permanent, although plants beside roads and in parks possibly bring about some seasonality.

Deciduous and evergreen forests have a contrastive seasonality; the BRDF parameters of the deciduous forest type largely depend on season, but the evergreen forest type has a relatively small seasonality. The difference is caused by winter leaf drop in deciduous forests. As for the variability of the BRDF parameters (i.e., the magnitude of error bars), the land types covered with plants tend to have larger magnitudes than those of urban regions. If we strictly remove the pixels covered by plants from the urban region's pixels, it may decrease the uncertainties related to BRDF's seasonality.

Here we focus on the seasonal change of rice paddies; rice paddies are distributed broadly in plain regions in Japan and also around Tokyo (see Fig. 3). The $f_{\text {geo }}$ and $f_{\text {vol }}$ of the rice 


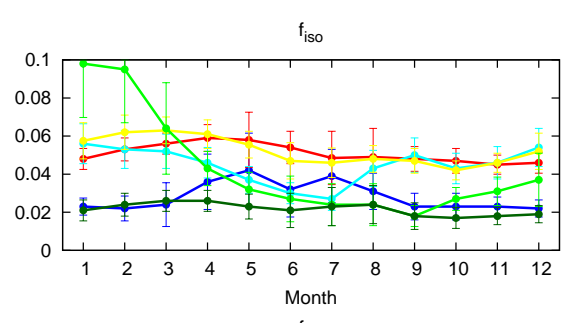

$f_{\text {vol }}$

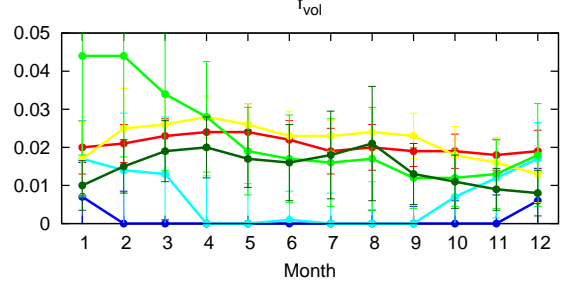

$f_{\text {geo }}$

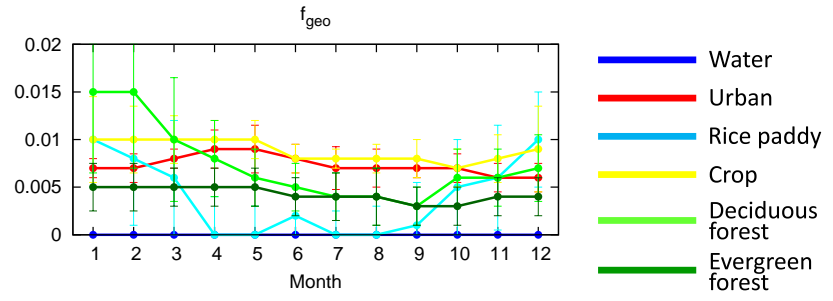

Figure 5. Monthly averages of the MODIS BRDF parameters, $f_{\text {iso }}$, $f_{\mathrm{vol}}$, and $f_{\text {geo }}$ for water (blue), urban (red), rice paddy (light blue), crop (yellow), deciduous forest (light green), and evergreen forest (green). The land cover type is derived from AVNIR-2.

paddy type changes abruptly to close to zero in summer. This is caused by the nature of the water type, which has almost zero values throughout the year for both $f_{\mathrm{vol}}$ and $f_{\mathrm{geo}}$, which represent directional components of BRDF. This means that the water type has a small directional dependence of scattering (except for sun glint reflection). The seasonal change of rice paddies is caused by water cover in summer, while in other seasons no water exists in rice paddies. We should note such an abrupt change of the BRDF characteristics during that season in areas covered by rice paddies which often surround urban regions in Japan.

\subsection{Tropospheric $\mathrm{NO}_{2}$ AMFs including the BRDF effect for each land cover type}

Tropospheric $\mathrm{NO}_{2}$ AMFs for the BRDF surface are calculated for each land type (Fig. 6). The results show that the AMFs largely depend on land cover type, and the order of the AMFs' magnitude between the different land cover types depends on season; in summer the AMF over urban surfaces is largest, while in winter the rice paddy areas have the largest AMF. The AMF of evergreen forest is smallest both in summer and winter. The difference between the largest and smallest AMF is up to several tens of percent or even a factor of two. The variability among the land cover types is larger in summer than in winter and stronger at noon than in the morning or evening, which suggests that the dependence of BRDF on land cover types becomes significant when the SZA is small.

Figure 7 shows the relative difference of the AMFs for calculations using approximated surface types, $A_{\mathrm{BRF}}, A_{\mathrm{BSA}}$, and $A_{\mathrm{WSA}}$, from the AMF for full BRDF treatment, $A_{\mathrm{BRDF}}$. The difference depends in a complex way on season and local time differences from $A_{\mathrm{BRDF}}$ being as large as $10 \%$ or more. With the exception of water and paddy surfaces, all land types show a similar behavior, indicating that the differences are mainly in their total reflectivity and not the angular distribution. For the water-covered surfaces, the differences from $A_{\mathrm{BRDF}}$ are generally small. In summer, the difference is zero since the $f_{\mathrm{vol}}$ and $f_{\text {geo }}$ of water are zero. The AMF of rice paddies in summer also has a small difference from $A_{\mathrm{BRDF}}$, which is similar to water since it is filled by water during this season as discussed in Sect. 3.1. This means that $A_{\mathrm{BRDF}}$ of rice paddies largely depends on season. The difference from the pure water type could be attributed to the non-water-covered regions of rice paddies, such as footpaths between rice fields.

The diurnal variations seen in Fig. 7 are a combination of changes in the AMF from the particular approximation used and changes in the AMF based on full BRDF calculations. In general, the AMF values for tropospheric $\mathrm{NO}_{2}$ increase with the increase of surface albedo. Figure 8 shows the diurnal variations of BRF, BSA, and WSA for the urban-type surface. In summer, for example, the values of BRF are smaller than those of BSA and WSA in the morning but larger in the afternoon except for the evening. This could partially explain the feature of the diurnal variations shown in Fig. 7; $A_{\mathrm{BRF}}$ is biased low in the summer morning but biased high in the afternoon, and behaves opposite to $A_{\mathrm{BSA}}$ and $A_{\mathrm{WSA}}$. The details of the AMF differences as function of local time depend on (a) the particularities of the BRDF parameterization used for the given area and (b) the specific geometry for the measurements over Tokyo from the assumed position of the geostationary satellite.

Although we cannot simply compare our results with Zhou et al. (2010), in which viewing angles largely changed instead of SZA, the results obtained by both studies are complementary; Zhou et al. (2010) showed that using LER instead of BRDF caused the differences of 0-20\% of tropospheric $\mathrm{NO}_{2}$ VCDs for changing viewing angles, and the present study showed $10 \%$ differences of tropospheric $\mathrm{NO}_{2}$ AMF (and approximately the same amounts of the differences in tropospheric $\mathrm{NO}_{2} \mathrm{VCDs}$ as well) for changing SZA. The values of $10 \%$ estimated in the present study are also consistent with the averaged values of $7 \%$ difference between BRDF- and LER-based tropospheric $\mathrm{NO}_{2}$ VCDs shown by Lin et al. (2013). 

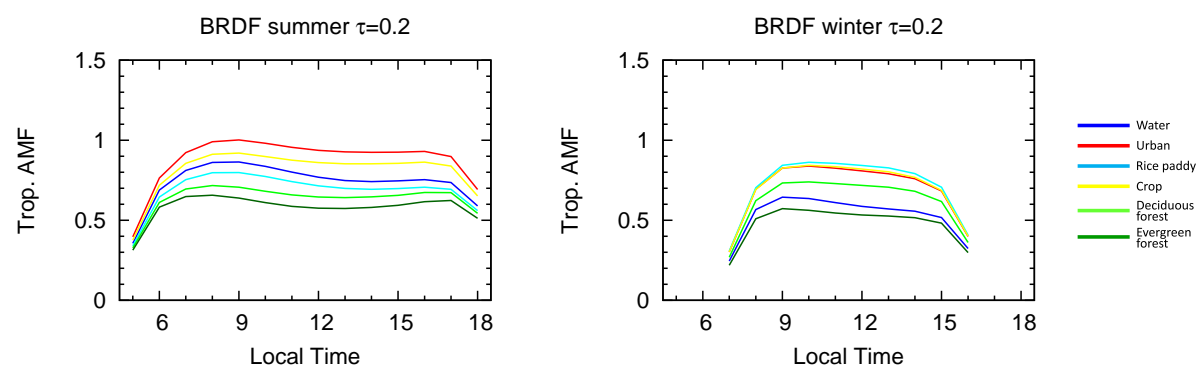

Figure 6. Tropospheric $\mathrm{NO}_{2} \mathrm{AMF}$ in summer (left) and winter (right) using BRDF surface. The colors indicate land cover types: water (blue), urban (red), rice paddy (light blue), crop (yellow), deciduous forest (light green), and evergreen forest (green). For all calculations an aerosol optical depth (AOD) of 0.2 is assumed.
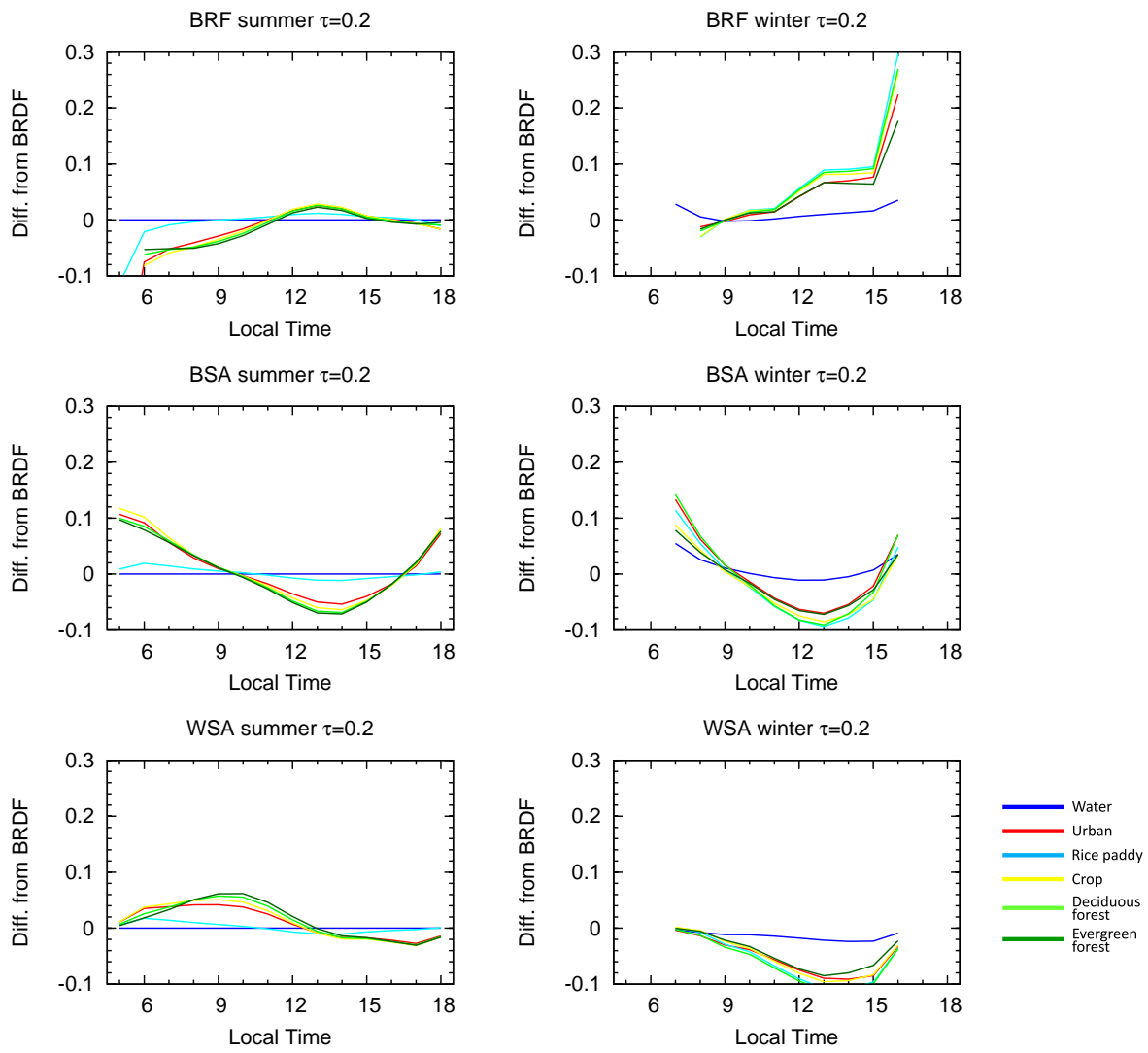

Figure 7. Relative difference of tropospheric $\mathrm{NO}_{2} \mathrm{AMFs}$ from the value obtained with full BRDF treatment when implementing the values of BRF (top), BSA (middle), and WSA (bottom) surface as LER in the RTM in summer (left) and winter (right). The colors indicate land cover types: water (blue), urban (red), rice paddy (light blue), crop (yellow), deciduous forest (light green), and evergreen forest (green). An aerosol optical depth (AOD) of 0.2 is assumed.

\subsection{Tropospheric $\mathrm{NO}_{2}$ BAMFs including the BRDF effect for each land cover type}

Figure 9 shows the vertical profile of BAMF for each land cover type calculated with full treatment of BRDF. The figure indicates that the BAMF differences among land cover types become larger in the lower layers. This means that the AMF dependence on the land cover types shown in Sect. 3.2 is mainly caused by the BAMF variability in the lower alti- tudes. As a result, it follows that whenever a high concentration of $\mathrm{NO}_{2}$ exists in the lower layers, the AMFs' difference among land cover types will become large. For example, if the $\mathrm{NO}_{2}$ concentrations in the lowermost layers $(0-1 \mathrm{~km}$ altitude) are 10 times larger than the ones of the original profile (Fig. 4), the variability of AMFs for BRDF among land cover types changes from 48 to $53 \%$ (in the case of 12:00 LT). Note that for real measurements, such a highly polluted spot often 

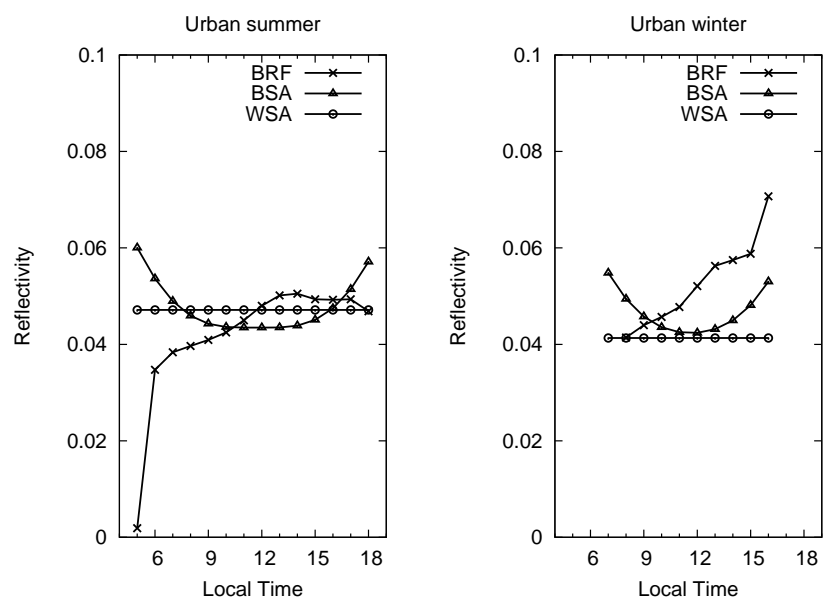

Figure 8. Reflectivity values of BRF, BSA, and WSA, which are implemented as LER in the RTM, in summer (left) and winter (right). The results for the urban surface type are shown.

involves an enhanced AOD, which could dampen the effect of $\mathrm{NO}_{2}$ enhancement (see Sect. 3.4).

Figure 10 shows the relative differences of the BAMFs for BSA $\left(B_{\mathrm{BSA}}\right)$ from the BAMF for full BRDF treatment ( $\left.B_{\mathrm{BRDF}}\right)$. The results for $B_{\mathrm{BRF}}$ and $B_{\mathrm{WSA}}$ are shown in the Supplement. The differences from $B_{\mathrm{BRDF}}$ becomes larger in the lower altitudes, and the differences can be larger than $10 \%$. The results for $B_{\mathrm{BRF}}$ and $B_{\mathrm{WSA}}$ are also similar to the results for $B_{\mathrm{BRDF}}$. This suggests that using BRF, BSA, or WSA instead of BRDF as an approximation of the surface albedo causes an error which depends on where the $\mathrm{NO}_{2}$ is located in the atmosphere, the difference becoming large if a high concentration of $\mathrm{NO}_{2}$ exists in the lowest layers. Figure 10 suggests that the tropospheric $\mathrm{VCD}$ of $\mathrm{NO}_{2}$ will be underestimated in the morning (due to larger BAMF) and overestimated in the afternoon (due to smaller BAMF) in the case of the BSA approximation. In the winter case, for example, the amounts of the underestimation and overestimation reach 15 and $9 \%$, respectively, when we assume 10 times larger concentration of $\mathrm{NO}_{2}$ in the lowest layer (0-1 km altitude). Note that the occurrence of underestimation or overestimation depends on the relative azimuth and thus the location of the satellite. In other words, the local time dependence depends on whether the relative location of a geostationary satellite is west or east of the observation point on the surface. In the present study, the satellite is assumed to be located in the west of the observation point. If the location of the satellite is different, the result will be different.

Heckel et al. (2011) also obtained a similar result for the combination of wrong surface albedo and a high concentration of $\mathrm{NO}_{2}$; the authors showed a case where large AMF errors occurred if the surface albedo was wrong due to the coarse spatial resolution and if a high concentration of $\mathrm{NO}_{2}$ exists only over such a surface. In that case, the AMF value changed from 0.7 to 0.4 if they used MODIS-BSA (higher resolution) instead of GOME-LER (lower resolution) for surface reflectance.

\subsection{Effect of aerosols}

Figure 11 shows the relative difference of the AMFs for approximated BRDF surface types, $A_{\mathrm{BRF}}, A_{\mathrm{BSA}}$, and $A_{\mathrm{WSA}}$, from the AMF for BRDF, $A_{\mathrm{BRDF}}$ for AOD of 1.0. For better comparison, Figure 10 shows only the results for the urban type at different AOD values (0.2 and 1.0). Again, we assume the constant $\mathrm{NO}_{2}$ profile shown in Fig. 4. Compared with Fig. 7, where AOD of 0.2 is assumed, smaller variability of AMF can be seen among land cover types in Fig. 11. In other words, the values of AMF for all land cover types tend to converge in Fig. 11. This can be attributed to the fact that larger scattering of aerosols weakens the importance of the surface term on the radiation field and thus decreases the dependence on the BRDF of different land cover types. Figure 10 indicates that the AMF computed using the WSA has the smallest difference from that based on the full BRDF. This suggests that not considering the angular dependence at all (i.e., WSA) is better than an incomplete implementation (i.e., BRF and BSA) of angle dependence. In summary, the importance of BRDF on the AMFs decreases for increasing AOD.

\subsection{Effect of the AMF differences on the $\mathrm{NO}_{2} \mathrm{VCDs}$}

Finally, we estimated the effect of the AMF differences mentioned above on the retrievals of tropospheric $\mathrm{NO}_{2} \mathrm{VCDs}$. In this estimate, we neglect the effect of stratospheric $\mathrm{NO}_{2}$ and assume that the tropospheric $\mathrm{NO}_{2}$ slant column density (SCD) can be obtained precisely. Assuming that the tropospheric $\mathrm{NO}_{2}$ VCD calculated by using BRDF is the true value, we calculated the relative difference or "error" $E_{i}$ of the tropospheric $\mathrm{NO}_{2} \mathrm{VCD}$ for an albedo type $i$ (i.e., BRF, BSA, and WSA) from the true VCD as follows:

$E_{i}=\left(V_{i}-V_{\text {true }}\right) / V_{\text {true }}$,

where $i$ denotes BRF, BSA, and WSA, $V_{i}=S_{\mathrm{BRDF}} / A_{i}$ is the tropospheric $\mathrm{NO}_{2} \mathrm{VCD}$ for the albedo type $i, V_{\text {true }}=$ $S_{\mathrm{BRDF}} / A_{\mathrm{BRDF}}$ is the true tropospheric $\mathrm{NO}_{2} \mathrm{VCD}$, which is calculated by using BRDF, and $V$ and $S$ are VCD and SCD, respectively.

Figure 13 shows the $E_{i}$ for the urban surface type. We can see that the difference is up to $10 \%$ in most cases, and the occurrence of underestimation or overestimation depends on season and local time. Focusing on BSA, for example, several percent of underestimation occurs in the early morning, and a similar amount of overestimation occurs in the afternoon. In the Supplement, results for other albedo types are shown. Except for the water type and the summer case of the rice paddy type, the seasonal and local time variations of all $E_{i}$ are similar, which is expected from the results for the AMFs (see Sect. 3.2). 

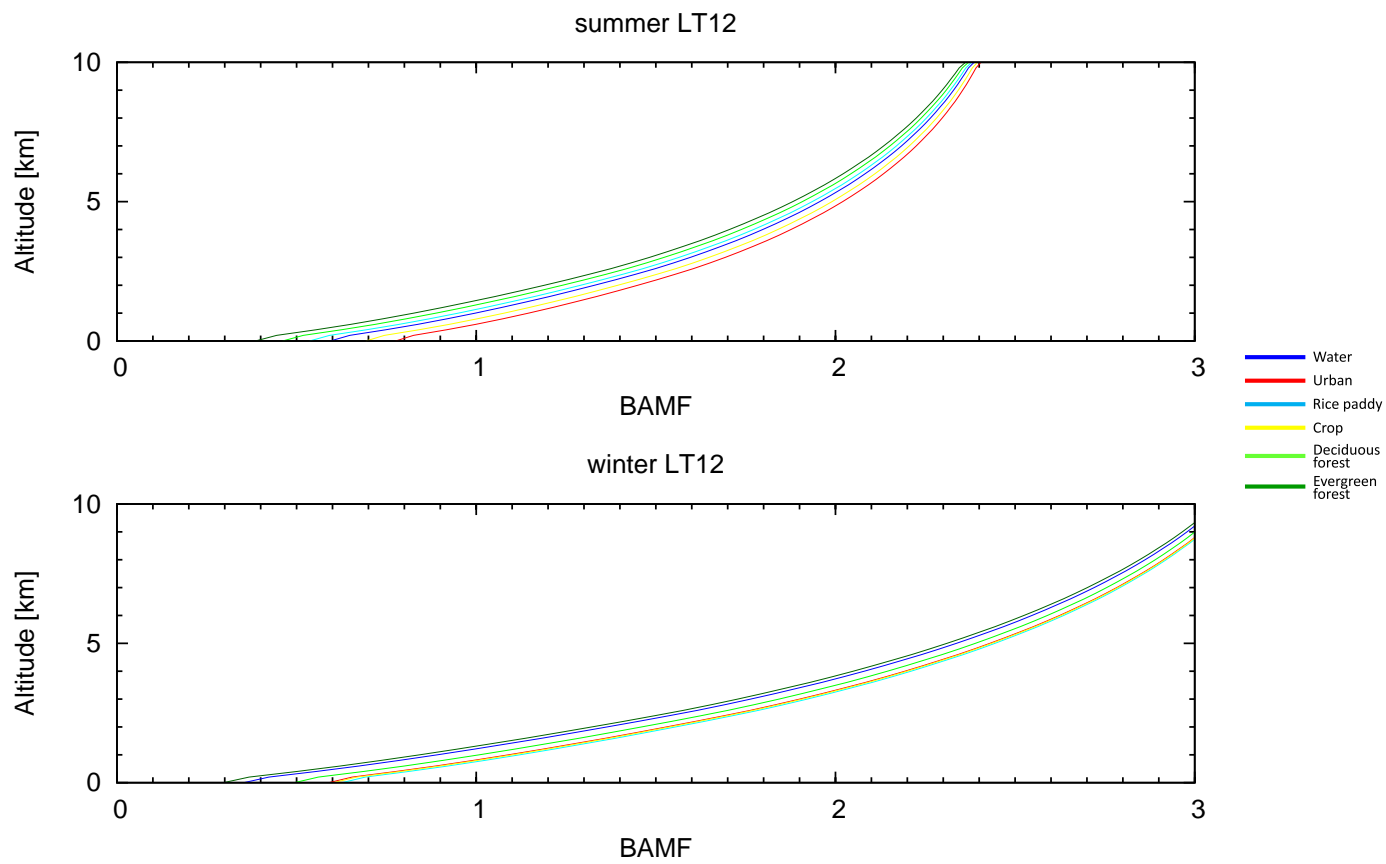

Figure 9. Tropospheric $\mathrm{NO}_{2}$ BAMF at 12:00 local time (LT) in summer (left) and winter (right) using BRDF surface. The colors indicate land cover types: water (blue), urban (red), rice paddy (light blue), crop (yellow), deciduous forest (light green), and evergreen forest (green). An aerosol optical depth (AOD) of 0.2 is assumed.
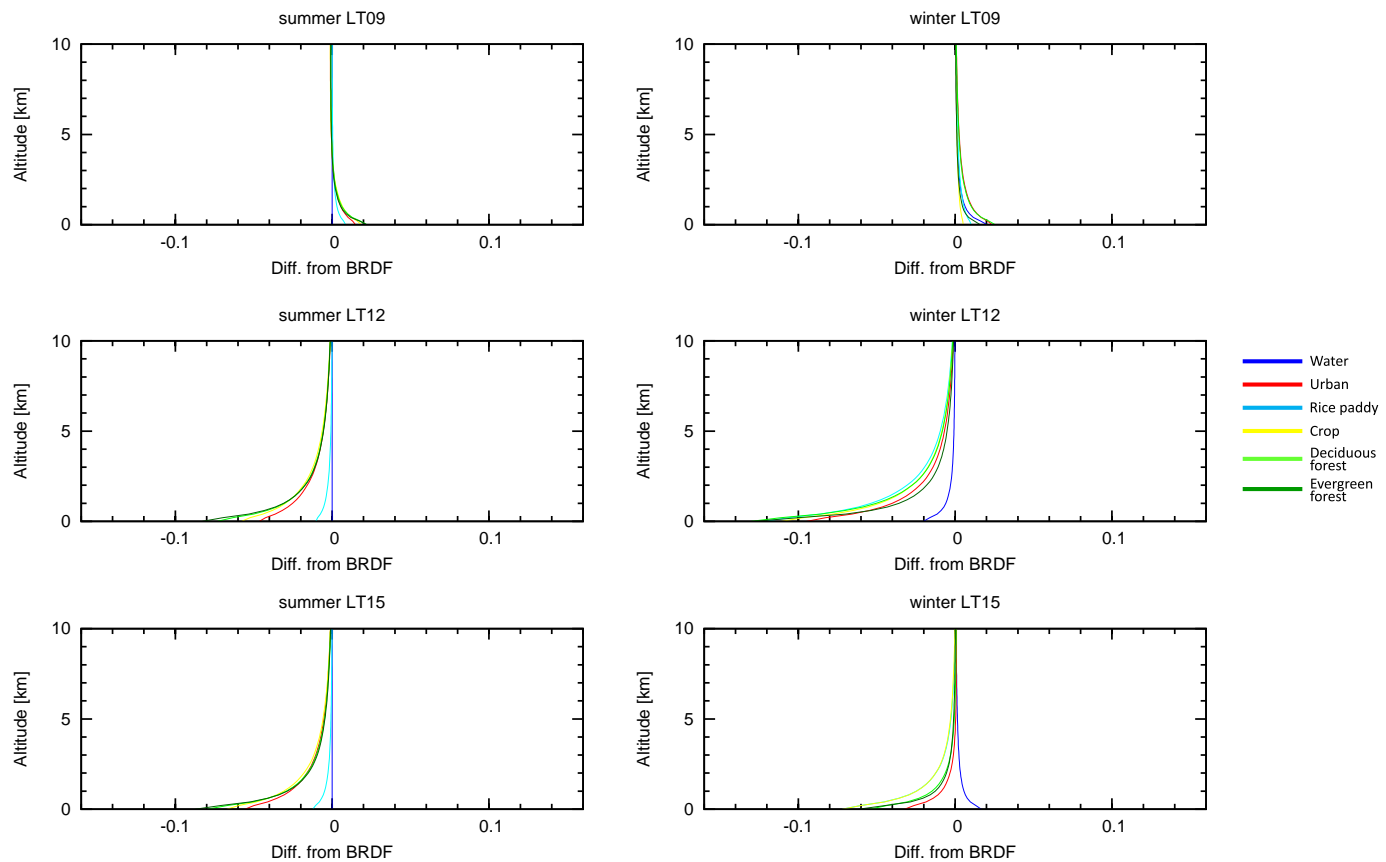

Figure 10. Relative difference of tropospheric $\mathrm{NO}_{2} \mathrm{BAMF}$ for various land cover types from the tropospheric $\mathrm{NO}_{2} \mathrm{BAMF}$ obtained using full BRDF treatment compared to results implementing the values of BSA surface as LER in the RTM. Panels at 09:00, 12:00, and 15:00 LT for summer (left) and winter (right) are shown. The colors indicate land cover types: water (blue), urban (red), rice paddy (light blue), crop (yellow), deciduous forest (light green), and evergreen forest (green). An aerosol optical depth (AOD) of 0.2 is assumed. 

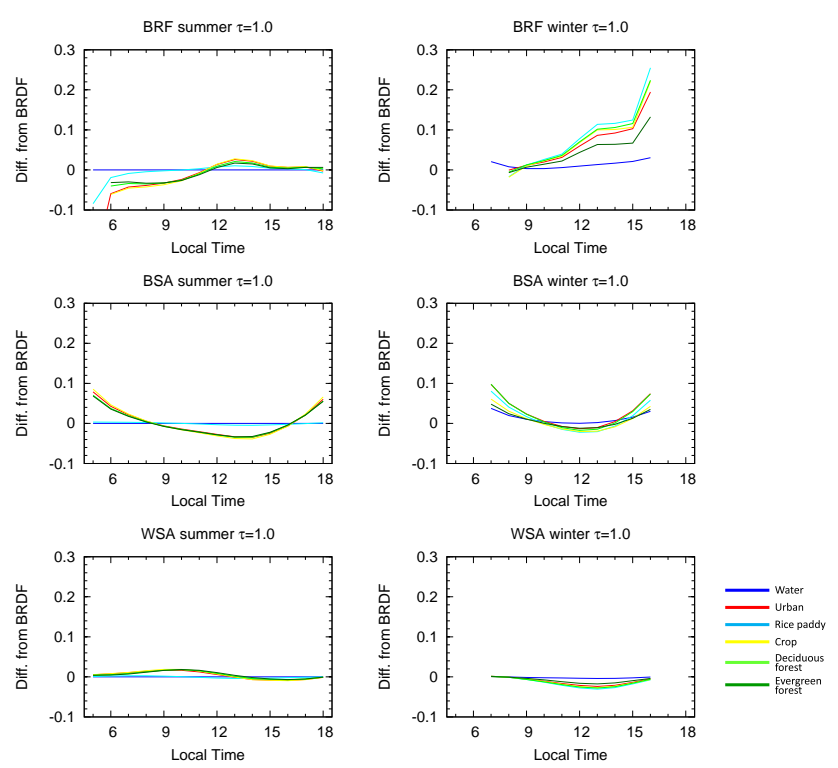

Figure 11. Relative difference of tropospheric $\mathrm{NO}_{2} \mathrm{AMFs}$ from the value obtained with full BRDF treatment when implementing the values of BRF (top), BSA (middle), and WSA (bottom) surface as LER in the RTM in summer (left) and winter (right). The colors indicate land cover types: water (blue), urban (red), rice paddy (light blue), crop (yellow), deciduous forest (light green), and evergreen forest (green). An aerosol optical depth (AOD) of 1.0 is assumed.

\section{Concluding remarks}

Assuming a geostationary satellite monitoring, we investigated the effect of surface reflectance anisotropy, BRDF, on the tropospheric $\mathrm{NO}_{2}$ measurements by calculating $\mathrm{AMF}$ and BAMF for different BRDF types. Besides BRDF, which fully considers surface reflectance anisotropy, we implemented three albedo values from different models (BRF, BSA, WSA), which have a different level of the consideration of surface reflectance anisotropy as an approximation, as LER in RTM. In our calculations, we also considered six land cover types: water, urban, paddy, crop, deciduous forest, and evergreen forest and their respective seasonal BRDFs.

Using MODIS BRDF results with AVNIR-2 land cover map data, we first developed an empirical model of BRDF parameters $\left(f_{\text {iso }}, f_{\text {vol }}, f_{\text {geo }}\right)$ specific to land cover types representative of the Tokyo area. Using the empirical model, we calculated AMFs and BAMFs for tropospheric $\mathrm{NO}_{2}$ with SCIATRAN. Results show that the AMF for tropospheric $\mathrm{NO}_{2}$ largely depends on land cover types; the variability among the land types is up to several tens of percent. If we neglect the reflectance anisotropy (i.e., use BRF, BSA, or WSA), the difference from $\mathrm{AMF}_{\mathrm{BRDF}}$ reaches $10 \%$ or more. The difference depends in a complicated way on season and local time. Incomplete implementation of surface reflectance anisotropy (i.e., BRF and BSA) can lead to even worse results than not considering the anisotropy of reflectance at all
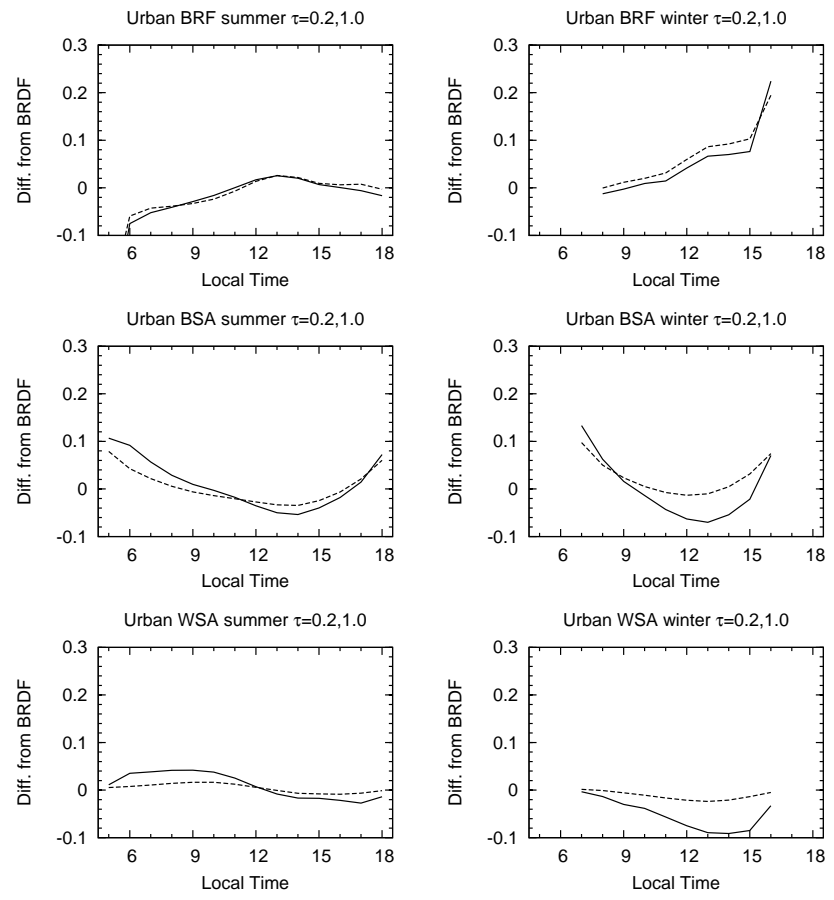

Figure 12. Relative difference of tropospheric $\mathrm{NO}_{2} \mathrm{AMFs}$ from the value obtained with full BRDF treatment when implementing the values of BRF (top), BSA (middle), and WSA (bottom) surface as LER in the RTM for urban type in summer (left) and winter (right). Aerosol optical depths (AODs) of 0.2 (solid curve) and 1.0 (dotted curve) are assumed, respectively.

(i.e., WSA). For lower altitudes, the BAMF difference among land cover types becomes larger. The difference of BAMFs computed using the BRF, BSA, and WSA from those derived using full BRDF treatment is also larger in the lower layers. If a high concentration of the tropospheric $\mathrm{NO}_{2}$ exists in the lower altitudes, failure to consider variations or BRDF will cause larger errors of the AMF. For example, if we use the BSA approximation instead of BRDF, the amounts of the underestimation (in the morning) and overestimation (in the afternoon) of the tropospheric $\mathrm{VCD}$ of $\mathrm{NO}_{2}$ reach 15 and $9 \%$, respectively, for the very polluted winter case with a 10 times larger concentration of $\mathrm{NO}_{2}$ in the lowest layer $(0$ $1 \mathrm{~km}$ altitude). The size and direction of the error depend on the relative location of the satellite to the observation point on the surface. At larger AOD (1.0), the differences in AMFs for the various surface types become smaller as the importance of BRDF decreases for large AOD.

In the present study, we rely on the MODIS-derived BRDF coefficients to be correct for all geometries and surfaces that we investigate. However, this assumption could be a source of uncertainty in the calculation of AMFs and BAMFs. For example, the range of local time (i.e., the combination of SZA and relative azimuth angle) of the MODIS BRDF products is limited, and it would be better to obtain the BRDF information for variations of local time, combined 

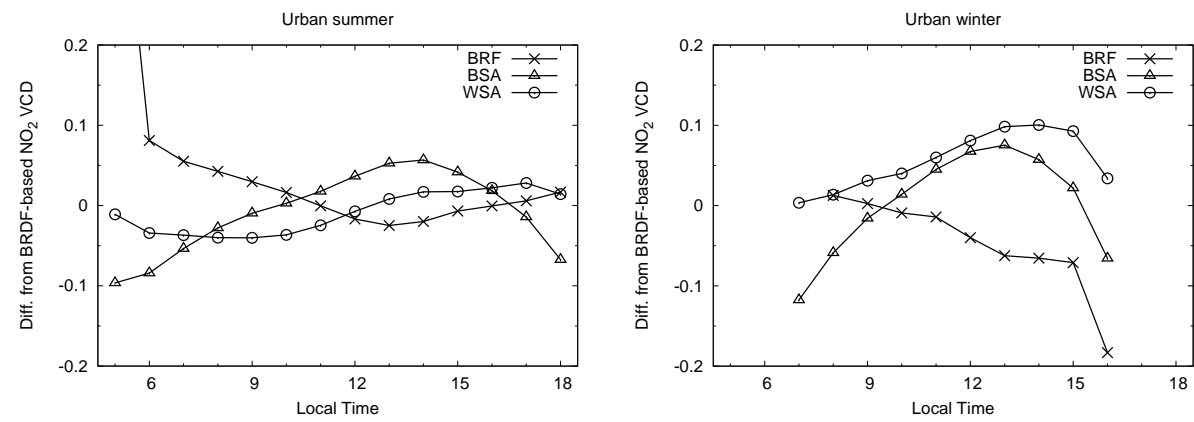

Figure 13. Relative difference of the tropospheric $\mathrm{NO}_{2}$ VCDs from the value obtained with full BRDF treatment when implementing the values of BRF, BSA, and WSA surface as LER in the RTM in summer (left) and winter (right). The results for the urban surface type are shown. The VCD for BRDF is assumed to be a true value.

with the validation of $\mathrm{NO}_{2}$ column densities by ground and/or airborne measurements. More comparison and validation of satellite-based BRDF measurements (e.g., Román et al. (2009) for forests; Susaki et al. $(2004,2007)$ for rice paddies) and the detailed evaluation of the dependence of BRDF parameters on SZA (Jin et al., 2003) will be needed from independent satellite measurements and ground measurements.

For real measurements, we also need to consider the problem of mixed surface types since the field of view of the sensor of the GMAP-Asia project is $10 \mathrm{~km}$ or less, which would usually include several surface types simultaneously. The present study focused on simple surface types to evaluate the range of possible effects. Although an exact treatment of a mixed BRDF is not straightforward, a good assumption would be that the effect of the mixed BRDF on the AMF is just the average of the individual effects, weighted by the contribution of the different surface types included in the field of view of the sensor. The effect of such mixed surface types on real measurements should be evaluated in future studies.

The findings in the present study are based on the geometry of the sun, an observed point on the ground surface, and a satellite (an observer), and are specific to the geostationary observation assumed in the present study. Detailed analysis for other satellite retrievals will be needed.

\section{The Supplement related to this article is available online at doi:10.5194/amt-7-3497-2014-supplement.}

Acknowledgements. We would like to thank Yasuko Kasai and other members of the APOLLO project and the Japan Society of Atmospheric Chemistry. We would also like to thank Kanako Muramatsu and Noriko Soyama for their useful comments on surface albedo. For the calculation of the SZA and other angles, we utilized the website of the National Astronomical Observatory of Japan (http://www.nao.ac.jp/koyomi/koyomix/koyomix.html).
The MODIS products were available at the NASA website, http://reverb.echo.nasa.gov. The High Resolution Land-Use and Land-Cover Map is available at the JAXA website, http://www.eorc.jaxa.jp/ALOS/lulc/lulc_jindex.htm. This work was supported by JSPS KAKENHI grant nos. 24710008 (K. Noguchi) and 22310004 (K. Kita). This work was carried out partly by the joint research program of CEReS, Chiba University (2013). This research was partly supported by the Coordination Funds for Promoting Space Utilization of the Ministry of Education, Culture, Sports, Science and Technology (MEXT), JAPAN.

Edited by: S. Beirle

\section{References}

Akimoto, H., Kasai, Y., and Kita, K., (Eds.): Planning a Geostationary Atmospheric Observation Satellite, National Institute of Information and Communications Technology, 2008.

Akimoto, H., Kasai, Y., Kita, K., Irie, H., Sagi, K., and Hayashida, S.: Geostationary Atmospheric Observation Satellite Plan in Japan (Invited), AGU Fall Meeting Abstracts, A51M-01, 2009.

Boersma, K. F., Eskes, H. J., Dirksen, R. J., van der A, R. J., Veefkind, J. P., Stammes, P., Huijnen, V., Kleipool, Q. L., Sneep, M., Claas, J., Leitão, J., Richter, A., Zhou, Y., and Brunner, D.: An improved tropospheric $\mathrm{NO}_{2}$ column retrieval algorithm for the Ozone Monitoring Instrument, Atmos. Meas. Tech., 4, 19051928, doi:10.5194/amt-4-1905-2011, 2011.

Bovensmann, H., Burrows, J. P., Buchwitz, M., Frerick, J., Noël, S., Rozanov, V. V., Chance, K. V., and Goede, A. P. H.: SCIAMACHY: Mission Objectives and Measurement Modes, J. Atmos. Sci., 56, 127-150, doi:10.1175/15200469(1999)056<0127:SMOAMM>2.0.CO;2, 1999.

Burrows, J. P., Weber, M., Buchwitz, M., Rozanov, V., LadstätterWeißenmayer, A., Richter, A., Debeek, R., Hoogen, R., Bramstedt, K., Eichmann, K.-U., Eisinger, M., and Perner, D.: The Global Ozone Monitoring Experiment (GOME): Mission Concept and First Scientific Results, J. Atmos. Sci., 56, 151-175, doi:10.1175/1520-0469(1999)056<0151:TGOMEG>2.0.CO;2, 1999.

Callies, J., Corpaccioli, E., Eisinger, M., Hahne, A., and Lefebvre, A.: GOME-2 Metop's second-generation sensor for operational ozone monitoring, ESA Bulletin, 102, 28-36, 2000. 
Fukue, K., Igarashi, T., Osawa, Y., Shimoda, H., Matsuoka, R., and Kawata, Y.: Advanced Visible and Near-Infrared Radiometer type 2 (AVNIR-2), Proc. SPIE, 2957, 208-215, 1997.

Grell, G. A., Peckham, S. E., Schmitz, R., McKeen, S. A., Frost, G., Skamarock, W. C., and Eder, B.: Fully coupled "online" chemistry within the WRF model, Atmos. Environ., 39, 6957-6975, doi:10.1016/j.atmosenv.2005.04.027, 2005.

Heckel, A., Kim, S.-W., Frost, G. J., Richter, A., Trainer, M., and Burrows, J. P.: Influence of low spatial resolution a priori data on tropospheric $\mathrm{NO}_{2}$ satellite retrievals, Atmos. Meas. Tech., 4, 1805-1820, doi:10.5194/amt-4-1805-2011, 2011.

Hess, M., Koepke, P., and Schult, I.: Optical Properties of Aerosols and Clouds: The Software Package OPAC, Bull. Amer. Meteorol. Soc., 79, 831-844, doi:10.1175/15200477(1998)079<0831:OPOAAC>2.0.CO;2, 1998.

Jacob, D. J., Crawford, J. H., Kleb, M. M., Connors, V. S., Bendura, R. J., Raper, J. L., Sachse, G. W., Gille, J. C., Emmons, L., and Heald, C. L.: Transport and Chemical Evolution over the Pacific (TRACE-P) aircraft mission: Design, execution, and first results, J. Geophys. Res., 108, 9000, doi:10.1029/2002JD003276, 2003.

Jin, Y., Schaaf, C. B., Woodcock, C. E., Gao, F., Li, X., Strahler, A. H., Lucht, W., and Liang, S.: Consistency of MODIS surface bidirectional reflectance distribution function and albedo retrievals: 2. Validation, J. Geophys. Res., 108, 4159, doi:10.1029/2002JD002804, 2003.

Justice, C., Vermote, E., Townshend, J., Defries, R., Roy, D., Hall, D., Salomonson, V., Privette, J., Riggs, G., Strahler, A., Lucht, W., Myneni, R., Knyazikhin, Y., Running, S., Nemani, R., Wan, Z., Huete, A., van Leeuwen, W., Wolfe, R., Giglio, L., Muller, J., Lewis, P., and Barnsley, M.: The Moderate Resolution Imaging Spectroradiometer (MODIS): land remote sensing for global change research, IEEE Trans. Geosci. Remote Sens., 36, 12281249, doi:10.1109/36.701075, 1998.

Levelt, P. F., van den Oord, G. H. J., Dobber, M. R., Malkki, A., Visser, H., de Vries, J., Stammes, P., Lundell, J. O. V., and Saari, H.: The ozone monitoring instrument, IEEE Trans. Geosci. Remote Sens., 44, 1093-1101, doi:10.1109/TGRS.2006.872333, 2006.

Lin, J.-T., Martin, R. V., Boersma, K. F., Sneep, M., Stammes, P., Spurr, R., Wang, P., Van Roozendael, M., Clémer, K., and Irie, H.: Retrieving tropospheric nitrogen dioxide over China from the Ozone Monitoring Instrument: effects of aerosols, surface reflectance anisotropy and vertical profile of nitrogen dioxide, Atmos. Chem. Phys. Discuss., 13, 21203-21257, doi:10.5194/acpd-13-21203-2013, 2013.

Lucht, W., Schaaf, C., and Strahler, A.: An algorithm for the retrieval of albedo from space using semiempirical BRDF models, IEEE Trans. Geosci. Remote Sens., 38, 977-998, doi:10.1109/36.841980, 2000.

Nicodemus, F. E., Richmond, J. C., Hsia, J. J., Ginsberg, I. W., and Limperis, T.: Geometrical considerations and nomenclature for reflectance, NBS MN-160, Natl. Bur. Stand. Rep., 1977.

Noguchi, K., Richter, A., Bovensmann, H., Hilboll, A., Burrows, J. P., Irie, H., Hayashida, S., and Morino, Y.: A feasibility study for the detection of the diurnal variation of tropospheric $\mathrm{NO}_{2}$ over Tokyo from a geostationary orbit, Adv. Space Res., 48, 1551-1564, doi:10.1016/j.asr.2011.06.029, 2011.

Noguchi, K., Richter, A., Burrows, J. P., Irie, H., and Kita, K.: A study of BRDF over Tokyo for the spaceborne measure- ments of atmospheric trace gases, Proc. SPIE, 8524 pp., 85242D, doi:10.1117/12.974818, 2012.

Román, M. O., Schaaf, C. B., Woodcock, C. E., Strahler, A. H., Yang, X., Braswell, R. H., Curtis, P. S., Davis, K. J., Dragoni, D., Goulden, M. L., Gu, L., Hollinger, D. Y., Kolb, T. E., Meyers, T. P., Munger, J. W., Privette, J. L., Richardson, A. D., Wilson, T. B., and Wofsy, S. C.: The MODIS (Collection V005) BRDF/albedo product: Assessment of spatial representativeness over forested landscapes, Remote Sens. Environ., 113, 24762498, doi:10.1016/j.rse.2009.07.009, 2009.

Roujean, J.-L., Leroy, M., and Deschanps, P.-Y.: A bidirectional reflectance model of the Earth's surface for the correction of remote sensing data, J. Geophys. Res., 97, 20455-20468, doi:10.1029/92JD01411, 1992.

Rozanov, A., Rozanov, V., Buchwitz, M., Kokhanovsky, A., and Burrows, J. P.: SCIATRAN 2.0-A new radiative transfer model for geophysical applications in the $175-2400 \mathrm{~nm}$ spectral region, Adv. Space Res., 36, 1015-1019, doi:10.1016/j.asr.2005.03.012, 2005.

Rozanov, V., Rozanov, A., Kokhanovsky, A., and Burrows, J.: Radiative transfer through terrestrial atmosphere and ocean: Software package SCIATRAN, J. Quant. Spectr. Rad. Trans., 133, 13-71, doi:10.1016/j.jqsrt.2013.07.004, 2014.

Russell, A. R., Perring, A. E., Valin, L. C., Bucsela, E. J., Browne, E. C., Wooldridge, P. J., and Cohen, R. C.: A high spatial resolution retrieval of $\mathrm{NO}_{2}$ column densities from OMI: method and evaluation, Atmos. Chem. Phys., 11, 8543-8554, doi:10.5194/acp-11-8543-2011, 2011.

Schaaf, C. B., Gao, F., Strahler, A. H., Lucht, W., Li, X., Tsang, T., Strugnell, N. C., Zhang, X., Jin, Y., Muller, J.-P., Lewis, P., Barnsley, M., Hobson, P., Disney, M., Roberts, G., Dunderdale, M., Doll, C., d'Entremont, R. P., Hu, B., Liang, S., Privette, J. L., and Roy, D.: First operational BRDF, albedo nadir reflectance products from MODIS, Remote Sens. Environ., 83, 135-148, doi:10.1016/S0034-4257(02)00091-3, 2002.

Sudo, K., Takahashi, M., Kurokawa, J., and Akimoto, H.: CHASER: A global chemical model of the troposphere 1. Model description, J. Geophys. Res., 107, 4339, doi:10.1029/2001JD001113, 2002.

Susaki, J., Hara, K., Park, J., Yasuda, Y., Kajiwara, K., and Honda, Y.: Validation of temporal BRDFs of paddy fields estimated from MODIS reflectance data, IEEE Trans. Geosci. Remote Sens., 42, 1262-1270, doi:10.1109/TGRS.2004.826798, 2004.

Susaki, J., Yasuoka, Y., Kajiwara, K., Honda, Y., and Hara, K.: Validation of MODIS Albedo Products of Paddy Fields in Japan, IEEE Trans. Geosci. Remote Sens., 45, 206-217, doi:10.1109/TGRS.2006.882266, 2007.

Takigawa, M., Niwano, M., Akimoto, H., and Takahashi, M.: Development of a one-way nested global-regional air quality forecasting model, SOLA, 3, 81-84, doi:10.2151/sola.2007-021, 2007.

Zhou, Y., Brunner, D., Boersma, K. F., Dirksen, R., and Wang, P.: An improved tropospheric $\mathrm{NO}_{2}$ retrieval for OMI observations in the vicinity of mountainous terrain, Atmos. Meas. Tech., 2, 401-416, doi:10.5194/amt-2-401-2009, 2009.

Zhou, Y., Brunner, D., Spurr, R. J. D., Boersma, K. F., Sneep, M., Popp, C., and Buchmann, B.: Accounting for surface reflectance anisotropy in satellite retrievals of tropospheric $\mathrm{NO}_{2}$, Atmos. Meas. Tech., 3, 1185-1203, doi:10.5194/amt-3-1185-2010, 2010. 